\title{
Assessment of Albumin Status in Hypertensive Patients with or Without Cataract in Eyes' Foundation Hospital, Itamogiri, Ogun State, Nigeria
}

\author{
Oladunjoye Z. A. ${ }^{1}$, Quadri J. A. ${ }^{2}$, Ojure M. A. ${ }^{2}$ \\ ${ }^{1}$ Department of Medical Laboratory Techniques, Ogun State College of Health Technology, Ilese- Ijebu, Nigeria \\ ${ }^{2}$ Department of Nutrition and Dietetics, Ogun State College of Health Technology, Ilese - Ijebu, Nigeria
}

Email address:

olaquadri2004@yahoo.co.uk (Quadri J. A.)

\section{To cite this article:}

Oladunjoye Z. A., Quadri J. A., Ojure M. A. Assessment of Albumin Status in Hypertensive Patients with or Without Cataract in Eyes' Foundation Hospital, Itamogiri, Ogun State, Nigeria. American Journal of Biomedical and Life Sciences. Vol. 5, No. 4, 2017, pp. $73-77$. doi: $10.11648 /$ j.ajbls.20170504.13

Received: June 12, 2016; Accepted: September 19, 2016; Published: July 20, 2017

\begin{abstract}
This research work assessed albumin concentration level in hypertensive patients with or without cataract at Eyes' Foundation Hospital at Itamogiri, Ijebu - Mushin in ijebu-East Local Government Area and General Hospital Ijebu-Ode both in Ogun State, Nigeria. Simple random sampling was used to select the 150 samples from the study area. Fifty (50) healthy staffs and individuals who volunteered to help with the research were used as control group, while group A (test) comprises of fifty (50) hypertensive patients without history of cataract and group B (test) comprises of fifty (50) hypertensive patients with history of cataract. Blood samples were taken under the same conditions in all individuals and analysed for albumin level using spectrophotometer. The findings showed that there was no significant difference in albumin level between the control group (Mean $\pm \mathrm{SD}=48.12 \pm 8.20 \mathrm{~g} / \mathrm{L}$ ) as compared with test group A (Mean $\pm \mathrm{SD}=49.19 \pm 10.19 \mathrm{~g} / \mathrm{L}$ ) but in comparing albumin level in control group and test group B, the findings showed that there was significant reduction in albumin concentration of test group B with Mean $\pm \mathrm{SD}=44.35 \pm 11.99 \mathrm{~g} / \mathrm{L}$ indicating hypertension (with cataract) had significantly decreased levels of plasma albumin when compared to non-cataract hypertensive patients. This shows that cataract could directly influence increase in serum albumin concentration of hypertensive patients. Salt restricted diet should be advised in such patients after evaluating serum electrolyte level which may delay maturation and progression of Cataract.
\end{abstract}

Keywords: Albumin, Cataract, Hypertension, Spectrophotometer

\section{Introduction}

Cataract refers to opacification of crystalline lens in the human eye. Globally, cataract accounts for $50 \%$ of blindness and remains the leading cause of visual impairment all over the world, despite improvements in surgical outcomes. Cataract accounts for approximately $50 \%$ of the world 37 million blind [1], this is of great concern particularly in developing countries where at least $80 \%$ of the blind resides. In Nigeria data from the recently concluded national survey put the prevalence of blindness at $0.78 \%$ with cataract accounting for $42.9 \%$ [2]. In spite of this high prevalence of cataract blind in Africa and Nigeria, the number of cataract surgeries per million populations per year, cataract surgical rate (CSR) is put at 500 and 300 respectively for these two regions [2]. This shows the region might be a long way from eliminating blindness from cataract.

The most common symptoms of cataract are, cloudy or blurry vision, colors seem faded, poor night vision, frequent prescription changes in eye glasses or contact lenses and double vision or multiple images in eye [3]. The risk factors for cataract formation, were aging, diabetes, smoking, eye surgery, poor nutrition, alcohol and others [4] Oxidative stress is a large increase in the cellular reduction potential (becoming less negative), or a large decreases in the reducing capacity of the cellular redox couples [5]. The protein aggregation and other gradual molecular changes that occur with aging almost cause widespread reduction in transparency and vision impaired [3]. In addition to altered membrane physiology and protein biochemistry, cataract 
development is accompanied by changes in lipid biochemistry, decreased enzyme activity, reduced glutathione levels, and diminished ATP production [6].

Serum albumin is produced by the liver, dissolved in blood plasma and is the most abundant blood protein inmammals. Albumin is essential for maintaining the oncotic pressure needed for proper distribution of body fluids between blood vessels and body tissues; without albumin, the high pressure in the blood vessels would force more fluids out into the tissues. It also acts as a plasma carrier by non-specifically binding several hydrophobic steroid hormones and as a transport protein for hemin and fatty acids. Too much or too little circulating serum albumin may be harmful.

Hypertension is sustained elevation of resting systolic BP $(\geq 140 \mathrm{~mm} \mathrm{Hg})$, diastolic BP $(\geq 90 \mathrm{~mm} \mathrm{Hg})$, or both. Hypertension with no known cause (primary; formerly, essential hypertension) is most common, hypertension with an identified cause (secondary hypertension) is usually due to chronic kidney disease or primary aldosteronism [7]. Usually, no symptoms develop unless hypertension is severe or longstanding. Hypertension is involved in the pathological pathway of cataract development through an inflammatory mechanism. Beyond that, Lee et al., [8] reported that hypertension could induce conformation structure alteration of proteins in lens capsules, thereby exacerbating the cataract formation. Although several plausible mechanisms have been proposed based on laboratory results, the conclusions from epidemiologic studies remain inconsistent. This research was carried out to determine the association between serum albumin and development of cataract, to examine if there is statistically significant difference between the serum albumin level in hypertensive patients with cataract and hypertensive patients without cataract.

\section{Materials and Method}

The study was conducted at Eyes' foundation at Itamogiriljebu-Mushin in Ogun State, South West Nigeria.

One hundred and fifty (150) respondents with or without cataracts was enrolled in this study. The subjects were divided into three groups consisting of fifty (50) hypertensive patients with cataract and other fifty (50) hypertensive patients are without cataract while fifty health individuals are used as control.

The blood samples were obtained by informed consent of the subjects and ethical committee of the hospital for albumin estimation.

\subsection{Procedure for Collection of Sample}

(1) Tourniquet was applied to the upper arm of the patients, sufficiently tight to restrict the venous flow and mark the vein standout,

(2) The patients were told to keep their arm straight and make a fist;

(3) The selected vein and site was cleaned using cotton wool and methylated spirit then, allow to dry.

(4) A disposal plastic syringe and pyrogen free needle was inserted smoothly to enter the vein and a $2 \mathrm{ml}$ of blood was collected into the plastic syringe by withdrawing it slowly and carefully.

(5) The tourniquet was loosened and a dry cotton wool was placed at the site of puncture.

(6) The patient were told to release there fist

(7) Two (2mls) of the blood was dispensed in an EDTA bottles for total Albumin estimation.

(8) The dispensed blood sample were centrifuged in a bucket centrifuge machine at $300 \mathrm{rpm}$ for 5 minutes; the plasma was separated into corresponding labelled bottles and plasma samples were then frozen at 20c until, samples were analysed.

\subsection{Methodology for Estimation of Serum Albumin}

MATERIALS USED: Needle and syringe, Centrifuge, Anti-coagulant bottles (Lithium-Heparin), Glove.

REAGENTS: BCG Reagent, Albumin Standard (4\%), Blank Reagent

SPECIMEN USED: Serum

\section{PRINCIPLE}

Under acidic conditions, serum albumin binds specifically with bromocresol green to form green colored complex. The albumin-BCG complex absorbs maximally at $578 \mathrm{~nm}$, the absorbance being directly proportional to the concentration of albumin in the sample.

Table 1. Method (Using Bromoscresol Green BCG).

\begin{tabular}{llll}
\hline Reagent & Test & Standard & Blank \\
\hline BCG Reagent & $5.0 \mathrm{ml}$ & $5.0 \mathrm{ml}$ & - \\
Blank Reagent & - & - & $5.0 \mathrm{ml}$ \\
Serum & $0.05 \mathrm{ml}$ & - & - \\
Standard & - & $0.05 \mathrm{ml}$ & - \\
Distilled water & - & - & $0.05 \mathrm{ml}$ \\
\hline
\end{tabular}

- Mixed well and stand at room temperature for 10 minutes

- Spectrophometer was set to zero with blank

- The absorbance was read at 578nm (red filter)

Calculation:

Grams of serum albumin $/ \mathrm{d}=\mathrm{Ab}$ Test $\mathrm{x}$ Conc. Of Standard

Ab Standard

\section{Results and Discussion}

The information was gathered among patients in the two study areas and were between age range of 30-70yrs. Out of the 150 samples collected from the study area, fifty (50) samples were used for the control group sample, these are healthy staffs and individuals who volunteered to help with the research while group A (test) comprises of fifty (50) hypertensive patients without history of cataract and group B (test) comprises of fifty (50) hypertensive patients with history of cataract. The data was analysed and presented in tables while inferential statistics of T-test was used to test for difference between the control group and the test group at $\mathrm{P}$ $<0.05$ level of significance. 
The table 2 above shows that $52(34.7 \%)$ respondents were male while 98 (65.3\%) were female. It shows that $43(28.7 \%)$ of the respondents were within the age of $30-40 \mathrm{yrs}, 29$ $(19.3 \%)$ were within the age of 41-50yrs, 31 (20.7\%) of them were within the age range of 51-60yrs while 47 (31.3\%) were within the age of $61.70 y r s$. Also, $50(33.3 \%)$ each of the respondents were hypertensive with cataract, hypertensive without cataract and normotensive respectively.

Table 2. Biodata of the respondents.

\begin{tabular}{llc}
\hline Variable & Frequency & Percentage \\
\hline Sex & 52 & 34.7 \\
Male & 98 & 65.3 \\
Female & & 28.7 \\
Age (yrs) & 43 & 19.3 \\
$30-40$ & 29 & 20.7 \\
$41-50$ & 31 & 31.3 \\
$51-60$ & 47 & 33.3 \\
$61-70$ & & 33.3 \\
Status & 50 & 33.3 \\
Hypertensive with cataract & 50 & \\
Normotensive & 50 & 50 \\
\hline
\end{tabular}

Table 3. Albumin concentration level for the Control and Tested group.

\begin{tabular}{lllll}
\hline Albumin Concentration & Control & Test (Group A) & T-Test & Df \\
\hline Mean \pm SD & $48.12 \pm 8.20 \mathrm{~g} / \mathrm{L}$ & $44.35 \pm 11.99 \mathrm{~g} / \mathrm{L}$ & & \\
Minimum Value & $30.73 \mathrm{~g} / \mathrm{L}$ & $17.10 \mathrm{~g} / \mathrm{L}$ & 0.6992 & \\
Maximum Value & $78.00 \mathrm{~g} / \mathrm{L}$ & $62.11 \mathrm{~g} / \mathrm{L}$ & & \\
\hline
\end{tabular}

For the test of Albumin level between the control and group A, the average mean of the control is $74.25 \mathrm{~g} / \mathrm{L}$ while that of the test group A is $75.14 \mathrm{~g} / \mathrm{L}$. The minimum value for the control group was $61.86 \mathrm{~g} / \mathrm{L}$ and the maximum value obtained for the control is $83.74 \mathrm{~g} / \mathrm{L}$ while for the test group $\mathrm{A}$, the minimum value obtained is $61.16 \mathrm{~g} / \mathrm{L}$ while the maximum value is $84.87 \mathrm{~g} / \mathrm{L}$ (Table 3 ).
When both means were compared using T-test inferential statistics at the significance level of $\mathrm{p}<0.05$, the t-test value obtained was 0.6992 (Table 3), signifying that no significant difference was observed within both sets of values. Both the control and test group A shows no significantly differences, indicating hypertension plays no influence in the levels of Albumin.

Table 4. Level of Albumin concentration for the Control and Tested group B.

\begin{tabular}{llllc}
\hline Albumin concentration & Control & Test (Group B) & T-Test & Df \\
\hline Mean \pm SD & $48.12 \pm 8.20 \mathrm{~g} / \mathrm{L}$ & $44.35 \pm 11.99 \mathrm{~g} / \mathrm{L}$ & & \\
Minimum Value & $30.73 \mathrm{~g} / \mathrm{L}$ & $17.10 \mathrm{~g} / \mathrm{L}$ & 1.833 & \\
Maximum Value & $78.00 \mathrm{~g} / \mathrm{L}$ & $62.11 \mathrm{~g} / \mathrm{L}$ & & \\
\hline
\end{tabular}

For the test of Albumin level between the control and group $\mathrm{B}$, the average mean of the control is $48.12 \mathrm{~g} / \mathrm{L}$ while that of the test group B is $44.35 \mathrm{~g} / \mathrm{L}$. The minimum value for the control group was $30.73 \mathrm{~g} / \mathrm{L}$ and the maximum value obtained for the control is $78.00 \mathrm{~g} / \mathrm{L}$ while for the test group $\mathrm{B}$, the minimum value obtained is $17.10 \mathrm{~g} / \mathrm{L}$ while the maximum value is $62.11 \mathrm{~g} / \mathrm{L}$ (Table 4 ). When both means were compared using T-test inferential statistics at the significance level of $\mathrm{p}<0.05$, the t-test value obtained was 1.833 (Table 4), signifying that no significant difference was observed within both sets of values. Both the control and test group B shows no significantly differences, indicating hypertension (with/without cataract) plays no influence in the levels of Albumin.

Table 5. Level of Albumin concentration for the Tested group $A \& B$.

\begin{tabular}{|c|c|c|c|c|c|}
\hline Albumin Concentration & Test (Group A) & Test (Group B) & T-Test & Df & Inference \\
\hline Mean \pm SD & $48.12 \pm 8.20 \mathrm{~g} / \mathrm{L}$ & $44.35 \pm 11.99 \mathrm{~g} / \mathrm{L}$ & & & \\
\hline Minimum Value & $30.73 \mathrm{~g} / \mathrm{L}$ & $17.10 \mathrm{~g} / \mathrm{L}$ & 2.175 & 98 & YES \\
\hline Maximum Value & $78.00 \mathrm{~g} / \mathrm{L}$ & $62.11 \mathrm{~g} / \mathrm{L}$ & & & \\
\hline
\end{tabular}

Table 5 shows the test of Albumin level between the treated group A \& B, the average mean of the group A is $48.12 \mathrm{~g} / \mathrm{L}$ while that of the test group B is $44.35 \mathrm{~g} / \mathrm{L}$.

When both means were compared using $\mathrm{T}$-test inferential statistics at the significance level of $p<0.05$, the $t$-test value obtained was 2.175 , signifying that a significant difference was observed within both groups. Group A (Hypertensive without cataract) showed a higher value for albumin when compared with that of group B (Hypertensive with cataract). This indicates that cataract conditions play a significant influence in the levels of Albumin in hypertensive patients. 


\section{Conclusion}

Serum albumin is produced by the liver, dissolved in blood plasma and is the most abundant blood protein in mammals. Albumin is essential for maintaining the oncotic pressure needed for proper distribution of body fluids between blood vessels and body tissues; without albumin, the high pressure in the blood vessels would force more fluids out into the tissues. It also acts as a plasma carrier by non-specifically binding several hydrophobic steroid hormones and as a transport protein for hemin and fatty acids.

This study revealed the albumin level concentration for the control and test groups (A \& B), the mean standard deviation was used in comparing the albumin level in control and test groups using $\mathrm{T}$-test inferential statistics at the significance level of $p<0.05$. The findings showed that there was no significant difference between the control samples and test group A (hypertensive patients without cataract) which means that hypertension does not necessarily affects albumin level.

Several studies revealed that hypertension is involved in the pathological pathway of cataract development through an inflammatory mechanism and beyond that, Lee et al. [8] reported that hypertension could induce conformation structure alteration of proteins in lens capsules, thereby exacerbating the cataract formation. This study also compares albumin level in control sample and test group B. The findings revealed that there was significant reduction in albumin concentration of test group B (hypertensive patients with cataract) with Mean $\pm \mathrm{SD}=44.35 \pm 11.99 \mathrm{~g} / \mathrm{L}$ when compared to the Mean $\pm \mathrm{SD}=48.12 \pm 8.20 \mathrm{~g} / \mathrm{L}$ of the control samples and this indicates that hypertension (with cataract) had significantly decreased levels of plasma albumin when compared to non-cataract hypertensive patients. This finding is similar to work done by Kayode et al., [9] which revealed significant reduction in plasma albumin concentration level in cataract patients and also in line with the results reported by Sabanayagam et al. [10], which state that, people with severe hypertension have a higher risk of cataract than those with mild hypertension. Several studies indicated a linear positive correlation between blood pressure and cataract risk $[11 ; 12]$ and the duration of hypertension is also an important factor, indicating a relationship between longer duration and increased cataract risk [13]. In conclusion, the findings showed that cataract condition plays a significant influence in the levels of Albumin in hypertensive patients by lowering the plasma albumin concentration.

\section{Recommendations}

(1) To prevent further progression of cataract, salt restricted diet may be advised in such patients after evaluating serum electrolyte level which may delay maturation and progression of Cataract.

(2) Smoking and alcoholic consumption should be discouraged by the subjects because several studies have shown that there is increased cataract formation in patients with higher alcohol consumption compared with patients who have lower or no alcohol consumption [14].

(3) Nutrition. The subjects should be encouraged in regular intake of antioxidants (such as vitamins A, C, and E) which has been thought to protect against the risk of cataracts [15].

\section{References}

[1] Resnikoff S, Pascolini D, Etya'ale D, Kocur I, Pararajasegaram R, Pokharel GP, (2004); Global data on visual impairment in the year 2002. Bull World Health Organ; 82: 844-51.

[2] Kyari F, Gudlavalleti M. V, Sivsubramaniam S, Gilbert C. E, Abdull M. M, Entekume G, Foster A. (2009); Prevalence of blindness and visual impairment in Nigeria: the National Blindness and Visual impairment study. Invest ophthalmol Vis Sci.; 50 (5): 2033-2039.

[3] Bruce D. W, Gray C. S, (1991); Beyond the cataract: visual and functional disability in elderly people. Age Ageing; 20: 389-391.

[4] Mac Carty C. A, Nanjan M. B, Taylor H. R. (2001); Vision impairment predicts 5 year mortality. Br J Ophthalmol.; 85: $322-326$.

[5] Schafer F. Q, Buettner G. R (2001); Redox environment of the cell as viewed through the redox state of the glutathione disulfide/ glutathione couple. Free Radic Biol Med, 30 (11): $1191-1212$.

[6] Beaulieu C, Rufiange M, Dumont M, Lachapelle P. (2009); Modulation of ERG retinal sensitivity parameters with light environment and photoperiod Documentiaophthamologica. 118: 89-99.

[7] Bautista L. E, Vera L. M, Arenas I. A, Gamarra G. (2004); Independent association between inflammatory markers (Ccreative protein, interleukin-6, and TNF-alpha) and essential hypertension. J Hum Hypertens; 19: 149-154.

[8] Lee S, Colditz G. A, Berkman L. F, Kawachi I. (2004); Prospective study of job insecurity and coronary heart disease in US women. Annals of Epidemilogy. 14: 24-30.

[9] Kayode S. Adedapo, Saudat T. Kareem, Charles O. Bekibele and Nnenna L. Nwobi (2012) Increased oxidative stress and non-enzymatic antioxidant levels in senile cataract. Department of Chemical Pathology, University College Hospital, Ibadan, Nigeria.

[10] Sabanayagam C, Anoop S. (2011); Serum calcium levels and Hypertension Among US Adults; J Clinical Hypertension; 13: 716-721.

[11] Richter G. M, Torres M, Choudhury F, Azen S. P, Varma R (2013); Risk factors for cortical, nuclear, posterior subcapsular, and mixed lens opacities: the Los Angeles Latino Eye Study. Ophthalmology 119: 547-554.

[12] Screenivas V, Prabhakar A, Badrinath S. S, Fernandes T, Roy I. S (1999); A rural population based case-control study of senile cataract in India. J Epidemiol 9: 327-326.

[13] Mukesh B. N, Le A, Dimitrov P. N, Ahmed S, Taylor H. R (2006); Development of cataract and associated risk factors. Arch Ophthalmol 124: 79-85. 
[14] Munoz R. F, Mrazek P. J and Haggerty R. J (1996); Institute of Medicine report on prevention of mental disorders: Summary and Commentary. American Psychologist 51: 11161122 .
[15] Bollinger K. E, Langston R. H (2008); What can patient expect from cataract sugery? Cleveland Clinic; Journal of medicine, 75 (3), 193-200. 